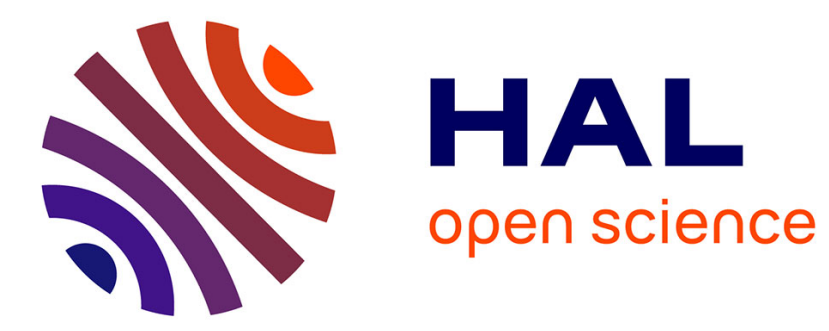

\title{
Sphingolipids from the human fungal pathogen Aspergillus fumigatus.
}

Thierry Fontaine

\section{To cite this version:}

Thierry Fontaine. Sphingolipids from the human fungal pathogen Aspergillus fumigatus.. Biochimie, 2017, 10.1016/j.biochi.2017.06.012 . pasteur-01580433

\section{HAL Id: pasteur-01580433}

\section{https://hal-pasteur.archives-ouvertes.fr/pasteur-01580433}

Submitted on 1 Sep 2017

HAL is a multi-disciplinary open access archive for the deposit and dissemination of scientific research documents, whether they are published or not. The documents may come from teaching and research institutions in France or abroad, or from public or private research centers.
L'archive ouverte pluridisciplinaire HAL, est destinée au dépôt et à la diffusion de documents scientifiques de niveau recherche, publiés ou non, émanant des établissements d'enseignement et de recherche français ou étrangers, des laboratoires publics ou privés.

\section{(1)(1) $\$(0)$}

Distributed under a Creative Commons Attribution - NonCommercial - ShareAlikel 4.0 


\section{Accepted Manuscript}

Sphingolipids from the human fungal pathogen Aspergillus fumigatus

Thierry Fontaine

PII: S0300-9084(17)30159-1

DOI: $\quad$ 10.1016/j.biochi.2017.06.012

Reference: $\quad \mathrm{BIOCHI} 5227$

To appear in: Biochimie

Received Date: 2 March 2017

Accepted Date: 21 June 2017

Please cite this article as: T. Fontaine, Sphingolipids from the human fungal pathogen Aspergillus fumigatus, Biochimie (2017), doi: 10.1016/j.biochi.2017.06.012.

This is a PDF file of an unedited manuscript that has been accepted for publication. As a service to our customers we are providing this early version of the manuscript. The manuscript will undergo copyediting, typesetting, and review of the resulting proof before it is published in its final form. Please note that during the production process errors may be discovered which could affect the content, and all legal disclaimers that apply to the journal pertain. 


\title{
Sphingolipids from the human fungal pathogen Aspergillus fumigatus
}

\author{
Thierry Fontaine
}

E-mail : thierry.fontaine@pasteur.fr

Unité des Aspergillus, Institut Pasteur, 25 rue du Docteur Roux, Paris, France

Keywords: Aspergillus fumigatus, glucosylceramide, GIPC, GPI

\section{Summary}

Sphingolipids (SPLS) are key components of the plasma membrane in yeast and filamentous fungi. These molecules are involved in a number of cellular processes, and particularly, SGLs are essential components of the highly polarized fungal growth where they are required for the formation of the polarisome organization at the hyphal apex. Aspergillus fumigatus, a human fungal pathogen, produce SGLs that are discriminated into neutral cerebrosides, glycosylinositolphosphoceramides (GIPCS) and glycosylphosphatidylinositol (GPI) anchors. In addition to complex hydrophilic head groups of GIPCs, $A$. fumigatus is, to date, the sole fungus that produces a GPI-anchored polysaccharide. These SPLs follow three different biosynthetic pathways. Genetics blockage leading to the inhibition of any SPL biosynthesis or to the alteration of the structure of SPL induces growth and virulence defects. The complete lipid moiety of SPLs is essential for the lipid microdomain organization and their biosynthetic pathways are potential antifungal targets but remains understudied.

\section{Introduction}

Aspergillus fumigatus is a saprotrophic filamentous fungus widely distributed in nature and is the most important airborne fungal pathogen in the world [1]. The continuous presence of conidia (asexual spores) in the air leads to their inhalation by humans and consecutively to allergic, pulmonary and invasive diseases [2]. The clinical presentation of A. fumigatus infection depends on the immune status of the host. Of the various pulmonary diseases, allergic bronchopulmonary aspergillosis (ABPA) and chronic pulmonary aspergillosis (CPA) generally occur in the immunocompetent individual while invasive pulmonary aspergillosis (IPA) manifests in the immunocompromised host [3]. Invasive aspergillosis (IA) remains the main cause of mortality in the patients undergoing allogeneic hematological stem cell transplantation [4,5].

Filamentous fungi are extremely polarized organisms, exhibiting continuous growth at their hyphal tip. Polarized growth requires an active vesicle trafficking to transport proteins and lipids required for the membrane extension and cell wall biosynthesis at the hyphal tip. The spitzenkorper is a vesicle structure and organizing center for hyphal growth [6]. Its integrity depends on microtubule, actin filament and also on the polarisome, a protein-ergosterol-sphingolipid complex localized at the plasma membrane of the apex. Ergosterol has been well studied as the main antifungal drug target. In contrast, the role of sphingolipids in fungal growth and as a putative antifungal target remains not well explored. Filamentous fungi are producing two types of sphingolipids, neutral and acidic. In this review, I will describe the knowledge on the structure and function of sphingolipids in A. fumigatus and discuss their putative importance during infection.

\section{Neutral sphingolipids}

Cerebrosides or monohexosylceramides are neutral glycosphingolipids produced by almost all eukaryotic organisms and also by few bacteria. In the fungal kingdom, cerebrosides have been described in many fungal species [7], with the exception of well-known yeasts such as Saccharomyces cerevisiae, Schizosaccharomyces pombe and Candida glabrata [8-10]. Their structures are conserved among fungal species studied so far. Fungal cerebrosides contain one glucose unit (GlcCer) or galactose unit (GalCer) covalently bound to the primary alcohol of an $\mathrm{N}$-acyl sphingoid base through a 
$\beta$-glycosidic linkage, and is mainly composed of a 9-methyl-4,8-sphingadienine $[7,11]$. Although the GalCer has been reported as a minor fungal cerebroside, its relative expression seems dependent on the fungal morphotype (yeast versus mycelium) as observed in the mycopathogen Sporothrix schenckii [12]. In A. fumigatus, GlcCer and GalCer have been purified from the mycelium and analysed by mass spectrometry and NMR [11,13] (Fig. 1). The GlcCer/GalCer ratio is dependent on isolates and growth condition, where GalCer may represent 20 to $50 \%$ of the total cerebroside amount [11]. The ceramide moiety is composed of a 9-methyl-4,8-sphindadienine as long chain base (LCB) in combination with either N-2'-hydroxyoctadecanoate or N-2'-hydroxyoctadecenoate (Fig. 1). GlcCer and GalCer may contain both ceramide structures but in variable proportion [11]. Although the inhibition of GlcCer biosynthetic pathway affects the conidial germination, hyphal growth, cell cycle and cell wall organisation [14,15], the presence of monohexosylceramide in conidia from Aspergillus species has never been investigated and its biological function remains poorly studied in A. fumigatus.

In fungal cells, GlcCer biosynthetic pathway starts with the condensation of a serine residue and the palmityol-Coenzyme A, leading to the formation of 3-ketosphinganine, which is further reduced to sphinganine through the activity of a 3-ketosphinganine reductase (Fig. 2) [7]. The sphinganine is then $\mathrm{N}$-acylated by a specific ceramide synthase, called BarA, to generate a ceramide. BarA activity has been identified as the target of the bacterial compound HSAF (Heat stable antifungal factor isolated from Lysobacter enzymogenes) [8]. Then, three enzymatic reactions occur sequentially that lead to $\Delta 4-$ and $\Delta 8$-desaturation and addition of a methyl group at the C-9 position on the LCB (Fig. 2)[16-18]. Finally, a $\beta$-glucosyltransferase, Gcs1 for glucosylceramide synthase, uses UDP-Glc as sugar donor to transfer a glucose unit onto the primary hydroxyl group to form $\beta$-glucosylceramide [19]. The transferase involved in the addition of the galactose residue on ceramide remains unknown.

In Cryptococcus neoformans, a human yeast pathogen, it has been shown that, once produced, GlcCer is exported to the plasma membrane, cell wall or secreted to the extracellular space in vesicles $[20,21]$. In Aspergillus species, the presence of exosomes has never been observed. GlcCer seems mainly localised at the plasma membrane. However, intracellular trafficking of fungal GlcCer has never been investigated [22]. Biological functions of GlcCer in fungi have been studied through gene deletion and inhibitory approaches. The interruption of any steps of the GlcCer biosynthetic pathway leads to a defect in growth, morphology and virulence in yeast and filamentous fungal pathogen [23-25]. Among Aspergillus species, GlcCer biosynthesis and functions have been mainly investigated in A. nidulans, a model filamentous fungus. The disruption of the initial step of GlcCer synthesis by gene deletion of barA or by inhibition in presence of HSAF strongly reduces the polarized growth and leads to the formation of enlarged and hyperbranched hyphae, with a cell wall alteration $[15,26]$. Similar phenotypes were observed when other biosynthetic steps were interrupted [27], showing that the structure of the ceramide, i.e., unsaturation and methylation of the LCB, is essential for the biological function of GlcCer. In these mutants, defect in the cell polarity was accompanied by a mislocalisation of lipid microdomains. Polarized hyphal growth requires the formation of sterol-sphingolipid domains at the plasma membrane. These domains are easily observed by filipin staining, a fluorescent dye that binds to ergosterol. The absence of filipin staining in GlcCer deficient strain or mutant with altered ceramide structure showed that GlcCer is essential for the polarisome organisation at the apex [26,27]. The function the methyl group at the $\mathrm{C}-9$, which is absent in plant and mammalian GlcCer structures [17], has been studied in yeast and filamentous fungi. The deletion of the specific methyl-transferase involved in GlcCer synthesis leads to defects in hyphal growth and in virulence of pathogenic fungal strains $[18,24,28,29]$. In C. albicans, the presence of GlcCer and its methyl group are critical for the sensitivity to the plant defensin peptide AFP1 [30], showing the involvement of the methyl group in the interaction of GlcCer and the AFP1 defensin peptide. Interestingly, the loss of methyl group of GlcCer in C. neoformans induces an increase of membrane permeability and a defect in cell membrane organization in neutral/alkaline $\mathrm{pH}$ [29], suggesting that the methyl group of GlcCer is important to the interaction with other membrane components and to initiate the formation of lipid raft by tightening sphingolipids and ergosterol together [31]. 


\section{Inositolphosphoceramide}

Inositolphosphoceramides (IPC) represent the second class of fungal sphingolipids where the ceramide moiety is composed of a very long chain hydroxylated fatty acid $\left(\mathrm{C}_{24}{ }^{-} \mathrm{C}_{26}\right)$ condensated to a $\mathrm{C}_{18^{-}}$ phytosphingosine (Fig. 1). Their abundance in the model yeast S. cerevisiae, representing $30 \%$ of phospholipid from the plasma membrane [32], eased investigation of their structure, metabolism and function. These sphingolipids are key signaling molecules in a number of yeast cellular processes including trafficking/exocytosis, endocytosis, actin cytoskeleton dynamics, membrane microdomains, calcium signaling, cell cycle control, stress resistance and nutrient uptake (see reviews [33-35]).

The biosynthesis of IPC begins in the endoplasmic reticulum by the synthesis of the ceramide moiety: 1) the condensation of palmitoyl-CoA with serine by the serine-palmitoyl transferase, 2) the 3ketodihydrosphingosine reduction to form the dihydrosphingosine (DHS) and 3) the attachment of a $\mathrm{C}_{24-26}$ fatty acid through an amide linkage by a ceramide synthase (Fig. 2). Although these biosynthetic steps are common to GlcCer and IPC pathways, these two components are produced by two distinct ceramide synthases in yeast and filamentous fungi $[23,26,36,37]$, suggesting that these two enzymes possess different substrate specificities. During IPC synthesis, the ceramide is hydroxylated at C-4 by Sur2 (also called BasA in filamentous fungi) to form phytoceramide [38]. Alternatively, DHS can be hydroxylated to form the phytosphingosine (PHS) prior the ceramide condensation [38]. In yeast, the $\mathrm{C}_{26}$ fatty acid moiety contain 0 to 4 hydroxyl groups at $\mathrm{C} 2, \mathrm{C} 3, \mathrm{C} 4$ and $\mathrm{C} 5$ respectively $[39,40]$. In $A$. fumigatus, the ceramide of IPC is mainly composed of $\mathrm{C}_{24: 0}$ with one hydroxyl group at C2 [41](Fig. 1). Once made, ceramide must be transported from ER to the Golgi apparatus where the polar head groups are added [42]. Inositol-phosphate is transferred from phosphatidylinositol onto the C1 hydroxyl of the ceramide to form IPC. This transfer is catalyzed by the IPC synthase encoded by AUR1 gene [43]. In S. cerevisiae, the deletion of AUR1 induced cell death. Similarly, AUR1 has been identified as an essential gene in $A$. fumigatus $[44,45]$. The inactivation of the IPC synthase by gene deletion or by aureobasidin $A$ inhibition leads to ceramide accumulation and defect in cytokinesis in yeast $[43,46]$. Although all known genes involved in IPC biosynthetic pathway are identified in $A$. fumigatus genome [47], none of them has been studied. The function of IPC has been investigated in A. nidulans, the filamentous model fungus. The replacement of $L A G A$, endocing for the serine-palmitoyl transferase, was constructed but could be only propagated as abnormal heterokaryon hyphae with severe growth defect, suggesting that $L A G A$ is an essential gene [26]. The use of inducible promoter (alcA) allowed to show that $L A G A$ is required for the apical growth and morphology [26]. In addition, the deletion of $B A S A$ coding for the sphingolipid C4 hydroxylase leads to a reduced growth with an hyperbranching of hyphae, an aberrant cell wall thickening and a strong defect in conidiation $[26,48]$. The apical growth defect in these mutants is correlated with the absence of filipin staining of sterol rich lipids domains at the apex.

Taking together all investigations on ceramide synthase in $A$. nidulans, data showed that filamentous fungi possess distinct pools of sphingolipids, GlcCer and IPC, which make independent contributions to polarized hyphal growth, probably through the formation of specialized lipid microdomains that regulate the organization of cytoskeleton $[6,26,48]$. Interestingly, the misorganisation of the sterolsphingolipid domain by high concentration of filipin leads to the mislocalization of proteins of the polarisome complex $[49,50]$. These data suggest those sterol-sphingolipid domains are essential for the polarisome establishment at the apex. A question that remains to be answered is, how the sterolsphingolipid rich domains are organized and positioned at the polarized growth sites?

\section{Head group and membrane anchored molecules through an IPC}

IPC also functions as a lipid anchor for molecules such as glycans to form glycosylinositolphosphoceramides (GIPC) and proteins described as glycosylphosphatidylinositolanchored proteins (GPI-APs). In S. cerevisiae, two GIPC head groups have been described, mannose residue and inositol-phosphomannose linked to the inositol ring to form MIPC and $\mathrm{M}(\mathrm{IP}){ }_{2} \mathrm{C}$ respectively 
[33]. In many other yeasts and filamentous fungi, head groups are more complex. In A. fumigatus, $\mathrm{M}(\mathrm{IP})_{2} \mathrm{C}$ has never been described, but the glycan moiety is extended up to four monosaccharides. Two GIPC types can be discriminated: a zwitterionic GIPC composed of a trisaccharide (Man-Man-GIcN) linked to IPC and acidic GIPCs where the glycans are linked to IPC through a mannose residue [41,51,52] (Table I). The glycan moiety contains 2-3 mannose, 0-2 galactofuranose with or without a phosphocholine group (Table I). The MITA gene, homolog of the yeast SUR1 and coding for a putative $\alpha$-mannosyl-transferase, is essential for the addition of the first mannose residue to the inositol ring in A. fumigatus [53]. Its deletion leads to the absence of GIPC except for the zwitterionic type and an increase of IPC. The mutant grows normally without any defect in the cell wall and membrane organization, and it is as virulent as the parental strain in mouse model of invasive aspergillosis [53]. A $\alpha-\mathrm{N}$-acetylglucosaminyl-transferase (Gnt-A), essential to the formation of zwitterionic GIPC, has been identified in A. fumigatus [54]. The mutant deficient in this transferase activity does not produce anymore zwitterionic GIPC but does not show any particular phenotype. Its virulence has not been tested [54].

GPI-anchored proteins (GPI-APs) are produced in all eukaryotic cells and are attached to the outer layer of the plasma membrane. In A. fumigatus, around $90 \mathrm{GPI}-\mathrm{APs}$ have been identified by genome sequence analysis [55] and a proteomic approach has shown that most of the major GPI-APs are involved in cell wall organization [56]. In A. fumigatus, the glycan moiety of the GPI anchor is composed of five mannose residues linked to a GlcN-IPC (Table I) [57], where the protein is covalently linked to the third mannose residue through a phosphoethanolamine bridge. The main difference with yeast GPI structures is the presence of a fifth mannose residue linked through an $\alpha-1,3-$ bond, which is added by a Golgi $\alpha$-mannosyl-transferase [57-59]. GPI biosynthetic pathway is an essential event to the fungal growth. Similar to other eukaryotic cells, it starts at the ER level on a phosphatidylinositol (PI) moiety [60,61]. However, in contrast to mammalian cells, after the GPI biosynthesis and the transfer of the protein onto the GPI anchor, a specific lipid remodeling occurs in fungi and has been well-studied in yeast $[60,62]$. This remodeling involves four sequential steps: inositol 2-0-deacylation, $\mathrm{PI}-2-\mathrm{O}-$ deacylation, $\mathrm{PI}$-reacylation with a long acyl chain and then substitution of the PI by a IPC. This lipid remodeling constitutes a second pathway in fungi leading to the formation of IPC and is required for the membrane localisation of GPI-anchored proteins, but also of other membrane proteins such as transporters [62]. In A. fumigatus, the deletion of PERA, coding for a phospholipase required for the second step of GPI lipid remodeling, leads to striking defects in growth and cell wall integrity [63]. A perA null mutant has decreased conidia production, increased susceptibility to triazole antifungal drugs, and is avirulent in a murine model of invasive pulmonary aspergillosis. These data suggest that GPI lipid remodeling in $A$. fumigatus may represent a new fungal specific antifungal drug target.

In addition to GIPC and GPI-APs, A. fumigatus produced a polysaccharide, the galactomannan (GM), which can be linked to a IPC. GM has been characterized for a longtime [64] and used as a circulating biomarker for the detection of invasive aspergillosis [65]. This polymer is composed of a main chain of $\alpha$-mannoside and short side-chains of galactofuranose residues. The GM remains an unique polymer in fungal kingdom since it occurs in three forms: free and released in the culture medium [64], covalently linked to cell wall $\beta-1,3$-glucans [66] and membrane bound through a GPI anchor, also called lipogalactomannan (LGM) [67]. The LGM contains the same IPC moiety as GIPC on which the mannan chain is linked to the glucosamine residue (Table I). In the GPI anchor, the glucosamine residue is linked to the 4-O position of the inositol ring whereas it is linked in 2-0 position in the zwitterionic GPIC. This structural difference explains the sensitivity of LGM to PI-PLC digestion and shown that the Gnt-A transferase is not involved in the GM biosynthesis $[54,67]$. Despite the presence of $G M$ in membrane and cell wall of both morphotypes of $A$. fumigatus, conidia and mycelium, its biosynthetic pathway remains poorly understood. Two pathways could be possibly involved: GPI anchor biosynthesis or glycosylation of IPC like in GIPC. Particularly, enzymes involved in mannan chain polymerization and transfer from plasma membrane onto cell wall $\beta$-glucans are not yet identified. 


\section{Role of SPLs in host-pathogen interaction and pathogenesis}

SPLs are involved in key cellular process in fungal pathogens and their biosynthesis pathways (GlcCer, IPC, GPI lipid remodeling) have been considered as promising research direction to uncover new antifungal targets [68]. Unfortunately, the lack of specificity and/or efficiency of already known molecules acting on these pathways in vitro does not allow their use against fungal infections in clinics. As example, serine-palmitoyl transferase or glucosylceramide synthase activities from human and fungi are blocked by the same inhibitors. The fungal specific enzyme activities, IPC synthase, are sensitive in vitro to aureobasidin A [69]. However, the presence of efflux transporter responsible for multidrug resistance in Aspergillus species, including $A$. fumigatus, leads to inefficient use of this drug as an antifungal agent [69]. These observations suggest that chemical investigations are required to design new drugs targeting specific fungal ceramide such as IPC or GPI lipid remodeling. However, the inhibition of ceramide synthesis has recently opened an alternative in the treatment of inflammation associated with fungal infections. In pulmonary chronic inflammatory diseases such as asthma or cystic fibrosis, Aspergillus infection enhances the sphingolipid de novo synthesis that leads to ceramide accumulation and mediates the inflammatory response in lung tissue. Interestingly, the serine palmitoyltransferase inhibition by myriocin has a dual anti-inflammatory and antifungal effect [70].

Fungal SPLs are also molecules involved in resistance to host defence molecules and to anti-fungal drugs or in the modulation of the host immune response [71]. At the plasma membrane level, SPLs are involved in fungal pathogenesis by regulating plasma membrane fluidity and permeability $[66,67,68]$. Lipid microdomains are also essential to the trafficking and to the localization of transporter such as efflux pumps that are required for multi-drug resistance [75] or in the modulation of drug-target interaction [70,71].

Plant and mammalian fungal pathogens, deficient in GlcCer, are less virulent $[24,27,29,78,79]$. The role of GlcCer, required for the full virulence of human fungal pathogen $C$. neoformans has been more investigated [25]. GlcCer deficient yeast does not present growth defect in acidic $\mathrm{pH}$ but do not growth at a neutral/alkaline $\mathrm{pH}$ which is essential for the fungal growth in host extracellular environment [25]. In contrast, the deletion of ISC1, coding for an inositol phosphosphingolipid-phospholipase C, enhances the sensitivity of yeast to oxidative stresses and to acidic environments. In a mouse model of cryoptococcosis in immunocompetent mice, $\triangle I S C 1$ mutant are less virulent and more sensitive to phagolysosome stress inside the macrophage, showing the importance of IPC structures in fungal pathobiology [80]. These data show that both fungal types of SPL, GlcCer and IPC, are required for the resistance to host environment. However, studies of the roles of these fungal SPL in virulence and resistance to host defences are largely missing. In Aspergillus species, both SPL types are essential to the early stage of development of fungal infection inside the lung ie conidial germination and hyphal growth $[14,48]$. However, the role of GlcCer and IPC biosynthetic pathways, SPL catabolism and their regulation to host environment during aspergilosis remain to be investigated.

Purified GIPC and LGM from A. fumigatus mycelium were tested for their capacity to induce immune response after intranasal inoculation to mice or in human T cell culture [81]. One of the major GIPC and LGM greatly promote the activation of Th17, and to some degree Th2 responses, in mice and humans. Interestingly, the comparison of LGM and free GM response suggest that IPC lipid anchor enhances a stronger Th17-inducing activity of the glycan moiety [81]. Fungal GlcCer may also interact with the human immune system. In a mouse model of allergy, intranasal administration of $A$. fumigatus extract results in the development of severe airway hyperreactivity [82]. Authors have demonstrated that fungal induced asthma is dependent on the activation of natural killer T cells (NKT) by a fungal component through a CD1d dependent glycolipid receptor. The key fungal antigen responsible for NKT cells activation is the GlcCer, called asperamide $B$, where its ceramide is composed of 9-methyl-4,8-dienine as LBC in combination with N-2'-hydroxy-3'-hexadecenoate [82,83] previously described as the major form of GlcCer in A. fumigatus [11]. Nevertheless, biological functions of fungal sphingolipids during infection process remains poorly understood. Investigations of regulations of SPL during infections, stress conditions and their effect on host immune response are needed. 


\section{Conclusion and perspectives}

Research on fungal sphingolipids have been developed in yeast and filamentous fungi model species, allowing the understanding of conserved biosynthetic pathways and their essential involvement in fungal polarized growth. However, the function of SPLs produced by fungal human pathogens during infection processes and their biosynthetic pathway as antifungal target remain poorly investigated. Interestingly, in Histoplasma capsulatum, ergosterol depletion significantly reduced the infectivity of alveolar macrophages of the yeast that persisted even after substituting ergosterol with cholesterol indicating the importance of fungal lipid structures in proper membrane organisation and infectivity [84]. A. fumigatus produced number of SPLs, GalCer, GlcCer, acidic and zwitterionic GIPC, GPI-anchors. Despite evidences for the involvement of fungal SPL in virulence and response against host defenses, the expression and regulation of these SPL species require for the adaptation of the fungus to host environment and infectivity remain poorly explored in case of $A$. fumigatus. The first step of infection development in lung tissue is the conidial germination that requires the synthesis of membrane components and induces strong modifications in cellular membrane organization. The switch from the quiescent life of resting conidia to active polarized growth requires highly regulated cellular machinery where sphingolipids and lipid microdomains take an essential place. Fungal SPL are associated to various lipid microdomains $[84,85]$. The dissection of membrane organization and dynamics of lipids during the conidial germination and polarized growth remains highly challenging. Lipidomic approach using recent advances in mass spectrometry and visualization of lipids, by high resolution microscopy, in native environment with appropriate probes that recognize naturally occurring lipids in live cell are essential technolgies to follow lipid remodeling during polarized growth and fungal infection. Such tools as fluorescently tagged lipid analogs, antibodies or lipid binding protein domains have been recently developed in yeast [86], but remain poorly used in filamentous fungi. Our knowledge on SPL and lipid microdomains in pathogenic fungi, is still in its infancy and requires further investigations to understand theirs functions in the adaptation to host environment during fungal infection development.

\section{References}

1. Latgé J-P. Aspergillus fumigatus and Aspergillosis. Clin. Microbiol. Rev. 1999;12:310-50.

2. Kwon-Chung KJ, Sugui JA. Aspergillus fumigatus-What Makes the Species a Ubiquitous Human Fungal Pathogen? PLoS Pathog. [Internet]. 2013 [cited 2016 Mar 15];9. Available from: http://www.ncbi.nlm.nih.gov/pmc/articles/PMC3857757/

3. Agarwal R, Chakrabarti A, Shah A, Gupta D, Meis JF, Guleria R, et al. Allergic bronchopulmonary aspergillosis: review of literature and proposal of new diagnostic and classification criteria. Clin. Exp. Allergy. 2013;43:850-73.

4. Frange P, Bougnoux M-E, Lanternier F, Neven B, Moshous D, Angebault C, et al. An update on pediatric invasive aspergillosis. Médecine Mal. Infect. 2015;45:189-98.

5. Segal BH. Aspergillosis. N. Engl. J. Med. 2009;360:1870-84.

6. Fischer R, Zekert N, Takeshita N. Polarized growth in fungi - interplay between the cytoskeleton, positional markers and membrane domains. Mol. Microbiol. 2008;68:813-26.

7. Barreto-Bergter E, Pinto MR, Rodrigues ML. Structure and biological functions of fungal cerebrosides. An. Acad. Bras. Ciênc. 2004;76:67-84. 
8. Saito K, Takakuwa N, Ohnishi M, Oda Y. Presence of glucosylceramide in yeast and its relation to alkali tolerance of yeast. Appl. Microbiol. Biotechnol. 2006;71:515-21.

9. Tavares PM, Thevissen K, Cammue BPA, François IEJA, Barreto-Bergter E, Taborda CP, et al. In Vitro Activity of the Antifungal Plant Defensin RsAFP2 against Candida Isolates and Its In Vivo Efficacy in Prophylactic Murine Models of Candidiasis. Antimicrob. Agents Chemother. 2008;52:4522-5.

10. Mattjus P. Glycolipid transfer proteins and membrane interaction. Biochim. Biophys. Acta BBA - Biomembr. 2009;1788:267-72.

11. Toledo MS, Levery SB, Straus AH, Suzuki E, Momany M, Glushka J, et al. Characterization of Sphingolipids from Mycopathogens: Factors Correlating with Expression of 2-Hydroxy Fatty Acyl (E)- $\Delta 3$-Unsaturation in Cerebrosides of Paracoccidioides brasiliensis and Aspergillus fumigatus. Biochemistry (Mosc.). 1999;38:7294-306.

12. Toledo MS, Levery SB, Straus AH, Takahashi HK. Dimorphic expression of cerebrosides in the mycopathogen Sporothrix schenckii. J. Lipid Res. 2000;41:797-806.

13. Boas MH, Egge H, Pohlentz G, Hartmann R, Bergter EB. Structural determination of N-2'hydroxyoctadecenoyl-1-O-beta-D-glucopyranosyl-9-methyl-4, 8-sphingadienine from species of Aspergillus. Chem. Phys. Lipids. 1994;70:11-9.

14. Levery SB, Momany M, Lindsey R, Toledo MS, Shayman JA, Fuller M, et al. Disruption of the glucosylceramide biosynthetic pathway in Aspergillus nidulans and Aspergillus fumigatus by inhibitors of UDP-Glc:ceramide glucosyltransferase strongly affects spore germination, cell cycle, and hyphal growth. FEBS Lett. 2002;525:59-64.

15. Li S, Calvo AM, Yuen GY, Du L, Harris SD. Induction of cell wall thickening by the antifungal compound dihydromaltophilin disrupts fungal growth and is mediated by sphingolipid biosynthesis. J. Eukaryot. Microbiol. 2009;56:182-7.

16. Ternes $P$, Franke $S$, Zähringer U, Sperling $P$, Heinz E. Identification and Characterization of a Sphingolipid $\Delta 4$-Desaturase Family. J. Biol. Chem. 2002;277:25512-8.

17. Ternes P, Sperling P, Albrecht S, Franke S, Cregg JM, Warnecke D, et al. Identification of Fungal Sphingolipid C9-methyltransferases by Phylogenetic Profiling. J. Biol. Chem. 2006;281:5582-92.

18. Fernandes CM, de Castro PA, Singh A, Fonseca FL, Pereira MD, Vila TVM, et al. Functional characterization of the Aspergillus nidulans glucosylceramide pathway reveals that LCB $\Delta 8$-desaturation and C9-methylation are relevant to filamentous growth, lipid raft localization and Psd1 defensin activity. Mol. Microbiol. 2016;102:488-505.

19. Leipelt M, Warnecke D, Zähringer U, Ott C, Müller F, Hube B, et al. Glucosylceramide Synthases, a Gene Family Responsible for the Biosynthesis of Glucosphingolipids in Animals, Plants, and Fungi. J. Biol. Chem. 2001;276:33621-9. 
20. Rodrigues ML, Travassos LR, Miranda KR, Franzen AJ, Rozental S, de Souza W, et al. Human Antibodies against a Purified Glucosylceramide from Cryptococcus neoformans Inhibit Cell Budding and Fungal Growth. Infect. Immun. 2000;68:7049-60.

21. Rodrigues ML, Nimrichter L, Oliveira DL, Frases S, Miranda K, Zaragoza O, et al. Vesicular Polysaccharide Export in Cryptococcus neoformans Is a Eukaryotic Solution to the Problem of Fungal Trans-Cell Wall Transport. Eukaryot. Cell. 2007;6:48-59.

22. Nimrichter L, Rodrigues ML. Fungal Glucosylceramides: From Structural Components to Biologically Active Targets of New Antimicrobials. Front. Microbiol. [Internet]. 2011 [cited 2017 Feb 23];2. Available from: http://journal.frontiersin.org/article/10.3389/fmicb.2011.00212/abstract

23. Rittenour WR, Chen M, Cahoon EB, Harris SD. Control of Glucosylceramide Production and Morphogenesis by the Bar1 Ceramide Synthase in Fusarium graminearum. PLOS ONE. 2011;6:e19385.

24. Ramamoorthy V, Cahoon EB, Thokala M, Kaur J, Li J, Shah DM. Sphingolipid C-9 Methyltransferases Are Important for Growth and Virulence but Not for Sensitivity to Antifungal Plant Defensins in Fusarium graminearum. Eukaryot. Cell. 2009;8:217-29.

25. Rittershaus PC, Kechichian TB, Allegood JC, Merrill AH, Hennig M, Luberto C, et al. Glucosylceramide synthase is an essential regulator of pathogenicity of Cryptococcus neoformans. J. Clin. Invest. 2006;116:1651-9.

26. Li S, Du L, Yuen G, Harris SD. Distinct Ceramide Synthases Regulate Polarized Growth in the Filamentous Fungus Aspergillus nidulans. Mol. Biol. Cell. 2006;17:1218-27.

27. Fernandes CM, de Castro PA, Singh A, Fonseca FL, Pereira MD, Vila TVM, et al. Functional characterization of the Aspergillus nidulans glucosylceramide pathway reveals that LCB $\triangle 8$-desaturation and C9-methylation are relevant to filamentous growth, lipid raft localization and Psd1 defensin activity. Mol. Microbiol. 2016;n/a-n/a.

28. Oura T, Kajiwara S. Candida albicans sphingolipid C9-methyltransferase is involved in hyphal elongation. Microbiology. 2010;156:1234-43.

29. Singh A, Wang H, Silva LC, Na C, Prieto M, Futerman AH, et al. Methylation of glycosylated sphingolipid modulates membrane lipid topography and pathogenicity of Cryptococcus neoformans. Cell. Microbiol. 2012;14:500-16.

30. Oguro Y, Yamazaki H, Takagi M, Takaku H. Antifungal activity of plant defensin AFP1 in Brassica juncea involves the recognition of the methyl residue in glucosylceramide of target pathogen Candida albicans. Curr. Genet. 2014;60:89-97.

31. Del Poeta M, Nimrichter L, Rodrigues ML, Luberto C. Synthesis and Biological Properties of Fungal Glucosylceramide. PLoS Pathog. [Internet]. 2014 [cited 2017 May 19];10. Available from: http://www.ncbi.nlm.nih.gov/pmc/articles/PMC3887071/ 
32. Patton JL, Lester RL. The phosphoinositol sphingolipids of Saccharomyces cerevisiae are highly localized in the plasma membrane. J. Bacteriol. 1991;173:3101-8.

33. Dickson RC, Sumanasekera C, Lester RL. Functions and metabolism of sphingolipids in Saccharomyces cerevisiae. Prog. Lipid Res. 2006;45:447-65.

34. Dickson RC. Roles for sphingolipids in Saccharomyces cerevisiae. Adv. Exp. Med. Biol. 2010;688:217-31.

35. Cowart LA, Obeid LM. Yeast Sphingolipids: Recent developments in understanding biosynthesis, regulation, and function. Biochim. Biophys. Acta. 2007;1771:421-31.

36. Ternes P, Wobbe T, Schwarz M, Albrecht S, Feussner K, Riezman I, et al. Two Pathways of Sphingolipid Biosynthesis Are Separated in the Yeast Pichia pastoris. J. Biol. Chem. 2011;286:11401-14.

37. Cheon SA, Bal J, Song Y, Hwang H-M, Kim AR, Kang WK, et al. Distinct roles of two ceramide synthases, CaLag1p and CaLac1p, in the morphogenesis of Candida albicans. Mol. Microbiol. 2012;83:728-45.

38. Grilley MM, Stock SD, Dickson RC, Lester RL, Takemoto JY. Syringomycin Action Gene SYR2 Is Essential for Sphingolipid 4-Hydroxylation in Saccharomyces cerevisiae. J. Biol. Chem. 1998;273:11062-8.

39. Smith SW, Lester RL. Inositol Phosphorylceramide, a Novel Substance and the Chief Member of a Major Group of Yeast Sphingolipids Containing a Single Inositol Phosphate. J. Biol. Chem. 1974;249:3395-405.

40. Megyeri M, Riezman H, Schuldiner M, Futerman AH. Making Sense of the Yeast Sphingolipid Pathway. J. Mol. Biol. 2016;428:4765-75.

41. Simenel C, Coddeville B, Delepierre M, Latgé J-P, Fontaine T. Glycosylinositolphosphoceramides in Aspergillus Fumigatus. Glycobiology. 2008;18:84-96.

42. Funato K, Riezman H. Vesicular and nonvesicular transport of ceramide from ER to the Golgi apparatus in yeast. J Cell Biol. 2001;155:949-60.

43. Nagiec MM, Nagiec EE, Baltisberger JA, Wells GB, Lester RL, Dickson RC. Sphingolipid synthesis as a target for antifungal drugs. Complementation of the inositol phosphorylceramide synthase defect in a mutant strain of Saccharomyces cerevisiae by the AUR1 gene. J. Biol. Chem. 1997;272:9809-17.

44. Hu W, Sillaots S, Lemieux S, Davison J, Kauffman S, Breton A, et al. Essential Gene Identification and Drug Target Prioritization in Aspergillus fumigatus. PLoS Pathog. [Internet]. 2007 [cited $2017 \quad$ Feb 2];3. Available from: http://www.ncbi.nlm.nih.gov/pmc/articles/PMC1817658/

45. Cheng J, Park T-S, Fischl AS, Ye XS. Cell Cycle Progression and Cell Polarity Require Sphingolipid Biosynthesis in Aspergillus nidulans. Mol. Cell. Biol. 2001;21:6198-209. 
46. Epstein S, Castillon GA, Qin Y, Riezman H. An essential function of sphingolipids in yeast cell division. Mol. Microbiol. 2012;84:1018-32.

47. Do JH, Park T-K, Choi D-K. A computational approach to the inference of sphingolipid pathways from the genome of Aspergillus fumigatus. Curr. Genet. 2005;48:134-41.

48. Li S, Bao D, Yuen G, Harris SD, Calvo AM. basA Regulates Cell Wall Organization and Asexual/Sexual Sporulation Ratio in Aspergillus nidulans. Genetics. 2007;176:243-53.

49. Alvarez FJ, Douglas LM, Konopka JB. Sterol-Rich Plasma Membrane Domains in Fungi. Eukaryot. Cell. 2007;6:755-63.

50. Takeshita N, Higashitsuji Y, Konzack S, Fischer R. Apical Sterol-rich Membranes Are Essential for Localizing Cell End Markers That Determine Growth Directionality in the Filamentous Fungus Aspergillus nidulans. Mol. Biol. Cell. 2008;19:339-51.

51. Toledo MS, Levery SB, Bennion B, Guimaraes LL, Castle SA, Lindsey R, et al. Analysis of glycosylinositol phosphorylceramides expressed by the opportunistic mycopathogen Aspergillus fumigatus. J. Lipid Res. 2007;48:1801-24.

52. Levery SB, Toledo MS, Straus AH, Takahashi HK. Comparative analysis of glycosylinositol phosphorylceramides from fungi by electrospray tandem mass spectrometry with low-energy collision-induced dissociation of $\mathrm{Li}(+)$ adduct ions. Rapid Commun. Mass Spectrom. RCM. 2001;15:2240-58.

53. Kotz A, Wagener J, Engel J, Routier F, Echtenacher B, Pich A, et al. The mitA gene of Aspergillus fumigatus is required for mannosylation of inositol-phosphorylceramide, but is dispensable for pathogenicity. Fungal Genet. Biol. FG B. 2010;47:169-78.

54. Engel J, Schmalhorst PS, Krüger AT, Müller CT, Buettner FFR, Routier FH. Characterization of an $\mathrm{N}$-acetylglucosaminyltransferase involved in Aspergillus fumigatus zwitterionic glycoinositolphosphoceramide biosynthesis. Glycobiology. 2015;25:1423-30.

55. Tekaia F, Latgé J-P. Aspergillus fumigatus: saprophyte or pathogen? Curr. Opin. Microbiol. 2005;8:385-92.

56. Bruneau JM, Magnin T, Tagat E, Legrand R, Bernard M, Diaquin M, et al. Proteome analysis of Aspergillus fumigatus identifies glycosylphosphatidylinositol-anchored proteins associated to the cell wall biosynthesis. Electrophoresis. 2001;22:2812-23.

57. Fontaine T, Magnin T, Melhert A, Lamont D, Latgé J, Ferguson MAJ. Structures of the glycosylphosphatidylinositol membrane anchors from Aspergillus fumigatus membrane proteins. Glycobiology. 2003;13:169-77.

58. Fankhauser C, Homans SW, Thomas-Oates JE, McConville MJ, Desponds C, Conzelmann A, et al. Structures of glycosylphosphatidylinositol membrane anchors from Saccharomyces cerevisiae. J. Biol. Chem. 1993;268:26365-74. 
59. Krüger AT, Engel J, Buettner FFR, Routier FH. Aspergillus fumigatus Cap59-like protein A is involved in $\alpha 1,3$-mannosylation of GPI-anchors. Glycobiology. 2016;26:30-8.

60. Kinoshita T, Fujita M. Biosynthesis of GPI-anchored proteins: special emphasis on GPI lipid remodeling. J. Lipid Res. 2016;57:6-24.

61. Fontaine T, Smith TK, Crossman A, Brimacombe JS, Latgé J-P, Ferguson MAJ. In Vitro Biosynthesis of Glycosylphosphatidylinositol in Aspergillus fumigatust. Biochemistry (Mosc.). 2004;43:15267-75.

62. Yoko-o T, Ichikawa D, Miyagishi Y, Kato A, Umemura M, Takase K, et al. Determination and physiological roles of the glycosylphosphatidylinositol lipid remodelling pathway in yeast. Mol. Microbiol. 2013;88:140-55.

63. Chung D, Thammahong A, Shepardson KM, Blosser SJ, Cramer RA. Endoplasmic reticulum localized PerA is required for cell wall integrity, azole drug resistance, and virulence in Aspergillus fumigatus. Mol. Microbiol. 2014;92:1279-98.

64. Latgé JP, Kobayashi H, Debeaupuis JP, Diaquin M, Sarfati J, Wieruszeski JM, et al. Chemical and immunological characterization of the extracellular galactomannan of Aspergillus fumigatus. Infect. Immun. 1994;62:5424-33.

65. Stynen D, Goris A, Sarfati J, Latgé JP. A new sensitive sandwich enzyme-linked immunosorbent assay to detect galactofuran in patients with invasive aspergillosis. J. Clin. Microbiol. 1995;33:497-500.

66. Fontaine T, Simenel C, Dubreucq G, Adam O, Delepierre M, Lemoine J, et al. Molecular organization of the alkali-insoluble fraction of Aspergillus fumigatus cell wall. J. Biol. Chem. 2000;275:27594-607.

67. Costachel C, Coddeville B, Latgé J-P, Fontaine T. Glycosylphosphatidylinositol-anchored Fungal Polysaccharide in Aspergillus fumigatus. J. Biol. Chem. 2005;280:39835-42.

68. Perdoni F, Signorelli P, Cirasola D, Caretti A, Galimberti V, Biggiogera M, et al. Antifungal activity of Myriocin on clinically relevant Aspergillus fumigatus strains producing biofilm. BMC Microbiol. [Internet]. 2015 [cited 2017 Feb 23];15. Available from: http://www.ncbi.nlm.nih.gov/pmc/articles/PMC4628231/

69. Zhong W, Jeffries MW, Georgopapadakou NH. Inhibition of Inositol Phosphorylceramide Synthase by Aureobasidin A in Candida and Aspergillus Species. Antimicrob. Agents Chemother. 2000;44:651-3.

70. Caretti A, Torelli R, Perdoni F, Falleni M, Tosi D, Zulueta A, et al. Inhibition of ceramide de novo synthesis by myriocin produces the double effect of reducing pathological inflammation and exerting antifungal activity against A. fumigatus airways infection. Biochim. Biophys. Acta BBA - Gen. Subj. 2016;1860:1089-97.

71. Guimarães LL, Toledo MS, Ferreira FAS, Straus AH, Takahashi HK. Structural diversity and biological significance of glycosphingolipids in pathogenic and opportunistic fungi. Front. 
Cell. Infect. Microbiol. [Internet]. 2014 [cited 2017 Feb 14];4. Available from: http://www.ncbi.nlm.nih.gov/pmc/articles/PMC4174763/

72. Farnoud AM, Toledo AM, Konopka JB, Del Poeta M, London E. Raft-Like Membrane Domains in Pathogenic Microorganisms. Curr. Top. Membr. 2015;75:233-68.

73. Palma-Guerrero J, Huang I-C, Jansson H-B, Salinas J, Lopez-Llorca LV, Read ND. Chitosan permeabilizes the plasma membrane and kills cells of Neurospora crassa in an energy dependent manner. Fungal Genet. Biol. FG B. 2009;46:585-94.

74. Palma-Guerrero J, Lopez-Jimenez JA, Pérez-Berná AJ, Huang I-C, Jansson H-B, Salinas J, et al. Membrane fluidity determines sensitivity of filamentous fungi to chitosan. Mol. Microbiol. 2010;75:1021-32.

75. Pasrija R, Panwar SL, Prasad R. Multidrug Transporters CaCdr1p and CaMdr1p of Candida albicans Display Different Lipid Specificities: both Ergosterol and Sphingolipids Are Essential for Targeting of CaCdr1p to Membrane Rafts. Antimicrob. Agents Chemother. 2008;52:694-704.

76. Healey KR, Challa KK, Edlind TD, Katiyar SK. Sphingolipids Mediate Differential Echinocandin Susceptibility in Candida albicans and Aspergillus nidulans. Antimicrob. Agents Chemother. 2015;59:3377-84.

77. Rella A, Farnoud AM, Del Poeta M. Plasma membrane lipids and their role in fungal virulence. Prog. Lipid Res. 2016;61:63-72.

78. Zhu C, Wang M, Wang W, Ruan R, Ma H, Mao C, et al. Glucosylceramides are required for mycelial growth and full virulence in Penicillium digitatum. Biochem. Biophys. Res. Commun. 2014;455:165-71.

79. Noble SM, French S, Kohn LA, Chen V, Johnson AD. Systematic screens of a Candida albicans homozygous deletion library decouple morphogenetic switching and pathogenicity. Nat. Genet. 2010;42:590-8.

80. Shea JM, Kechichian TB, Luberto C, Del Poeta M. The Cryptococcal Enzyme Inositol Phosphosphingolipid-Phospholipase C Confers Resistance to the Antifungal Effects of Macrophages and Promotes Fungal Dissemination to the Central Nervous System. Infect. Immun. 2006;74:5977-88.

81. Bozza S, Clavaud C, Giovannini G, Fontaine T, Beauvais A, Sarfati J, et al. Immune Sensing of Aspergillus fumigatus Proteins, Glycolipids, and Polysaccharides and the Impact on Th Immunity and Vaccination. J. Immunol. 2009;183:2407-14.

82. Albacker LA, Chaudhary V, Chang Y-J, Kim HY, Chuang Y-T, Pichavant M, et al. Invariant natural killer $\mathrm{T}$ cells recognize a fungal glycosphingolipid that can induce airway hyperreactivity. Nat. Med. 2013;19:1297-304. 
83. Chaudhary V, Albacker LA, Deng S, Chuang Y-T, Li Y, Umetsu DT, et al. Synthesis of fungal glycolipid asperamide $\mathrm{B}$ and investigation of its ability to stimulate natural killer $\mathrm{T}$ cells. Org. Lett. 2013;15:5242-5.

84. Tagliari L, Toledo MS, Lacerda TG, Suzuki E, Straus AH, Takahashi HK. Membrane microdomain components of Histoplasma capsulatum yeast forms, and their role in alveolar macrophage infectivity. Biochim. Biophys. Acta BBA - Biomembr. 2012;1818:458-66.

85. Malinsky J, Opekarová M, Grossmann G, Tanner W. Membrane Microdomains, Rafts, and Detergent-Resistant Membranes in Plants and Fungi. Annu. Rev. Plant Biol. 2013;64:501-29.

86. Singh P. Budding Yeast: An Ideal Backdrop for In vivo Lipid Biochemistry. Front. Cell Dev. Biol. [Internet]. 2017 [cited 2017 Feb 2];4. Available from: http://www.ncbi.nlm.nih.gov/pmc/articles/PMC5222803/

\section{Legends to figures}

Figure 1: Structures of sphingolipids on A. fumigatus. A structure of monohexosylceramides, $N-2^{\prime}-$ hydroxyoctadec-3-enoyl-1- $\beta$-D-glucopyranosyl-

(1); $N$-2'-hydroxyoctadec-3-enoyl-1- $\beta$-Dgalactopyranosyl- (2) and $N$-2'-hydroxyoctadecanoyl-1- $\beta$-D-glucopyranosyl- (3) 9-methyl-trans-4,trans8-sphingadienines. B: Structure of the inositolphosphoceramide identified in GIPC and GPI anchor.

Figure 2: Schematic representation of biosynthetic pathways of GlcCer and GIPC in fungi. (Enzymes are in italic) 
Table I : Structures of hydrophilic head groups linked to IPC described in Aspergillus fumigatus

\section{Structures of GIPC}

$\alpha-$ Man-(1,3)- $\alpha$-Man-(1,6)- $\alpha$-GlcN-(1,2)-Ins-P-Cer

$\alpha$-Man-(1,3)- $\alpha$-Man-(1,2)-Ins-P-Cer

$\alpha$-Man-(1,2)- $\alpha$-Man-(1,3)- $\alpha$-Man-(1,2)-Ins-P-Cer

$\alpha$-Man-(1,3)-[ $\beta$-Galf-(1,6)]- $\alpha$-Man-(1,2)-Ins-P-Cer

$\alpha$-Man-(1,2)- $\alpha$-Man-(1,3)-[ $\beta$-Galf-(1,6)]- $\alpha$-Man-(1,2)-Ins-P-Cer

$\beta$-Galf-(1,2)- $\alpha$-Man-(1,3)- $\alpha$-Man-(1,2)-Ins-P-Cer

$\beta$-Galf-(1,2)- $\alpha$-Man-(1,3)-[ $\alpha$-Man-(1,6)]- $\alpha$-Man-(1,2)-Ins-P-Cer

$\beta$-Galf-(1,2)- $\alpha$-Man-(1,3)-[ $\beta$-Galf-(1,6)]- $\alpha$-Man-(1,2)-Ins-P-Cer

Choline-P-6- $\beta$-Galf-(1,2)- $\alpha$-Man-(1,3)- $\alpha$-Man-(1,2)-Ins-P-Cer

Stucture of GPI-anchored GM

$\alpha$-Man-(1,2)- $\alpha$-Man-(1,2)- $\alpha$-Man-(1,2)- $\alpha$-Man-(1,6)- $\alpha$-GlcN-(1,4)-Ins-P-Cer

GM polysaccharide is linked to the fourth mannose residue though a glycosidic linkage

Stuctures of GPI-anchor from membrane bound proteins

$\alpha$-Man-(1,3)- $\alpha$-Man-(1,2)- $\alpha$-Man-(1,2)- $\alpha$-Man-(1,2)- $\alpha$-Man-(1,6)- $\alpha$-GlcN-(1,4)-Ins-P-Cer

$\alpha$-Man-(1,2)- $\alpha$-Man-(1,2)- $\alpha$-Man-(1,2)- $\alpha$-Man-(1,6)- $\alpha$-GlcN-(1,4)-Ins-P-Cer

Proteins are linked to the third mannose of the GPI anchor through a phosphoethanolamine

[51]

[51]

[51]

[41]

[41]

[41]

[41]

[67] group.

References

[41,51]

[41,51,52] 
A
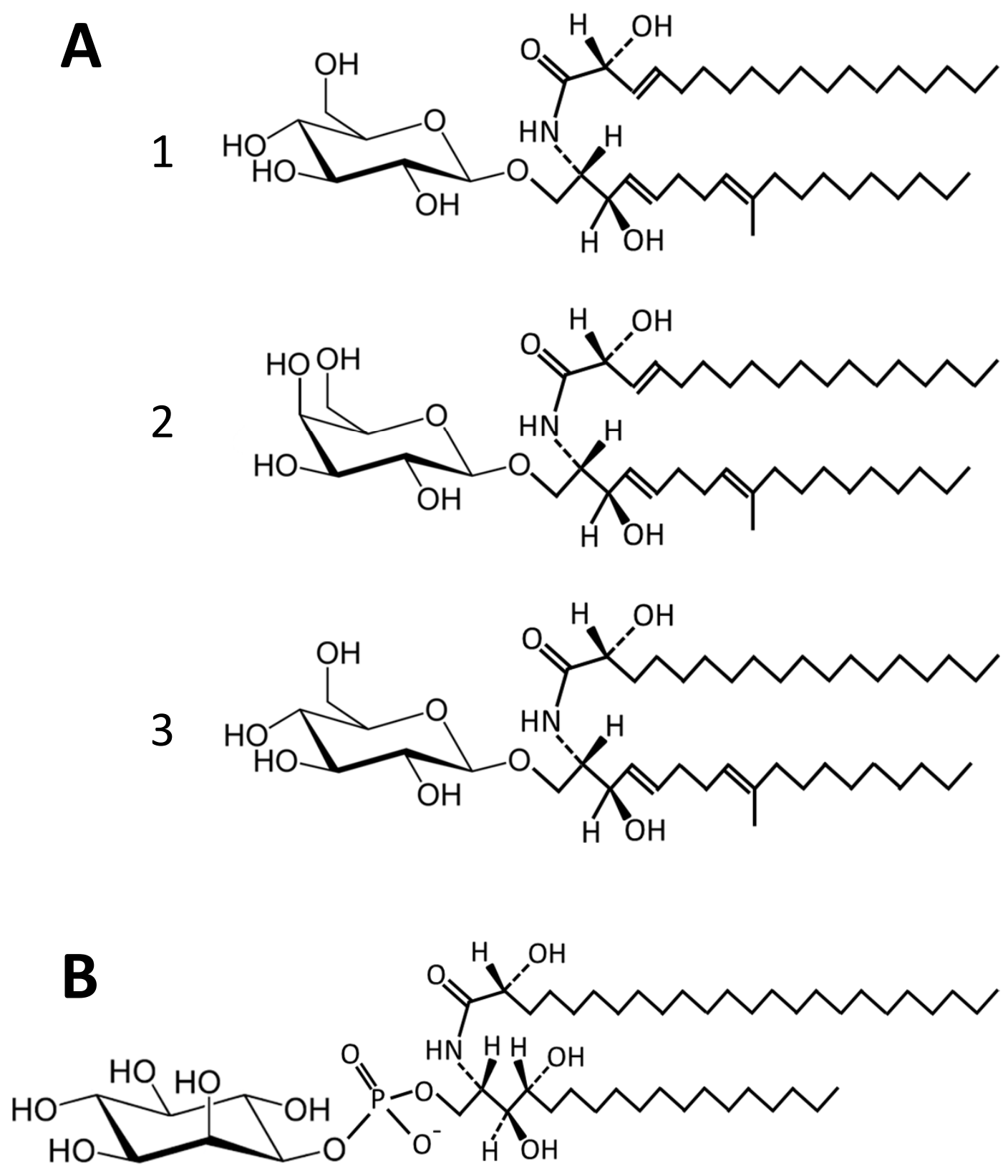


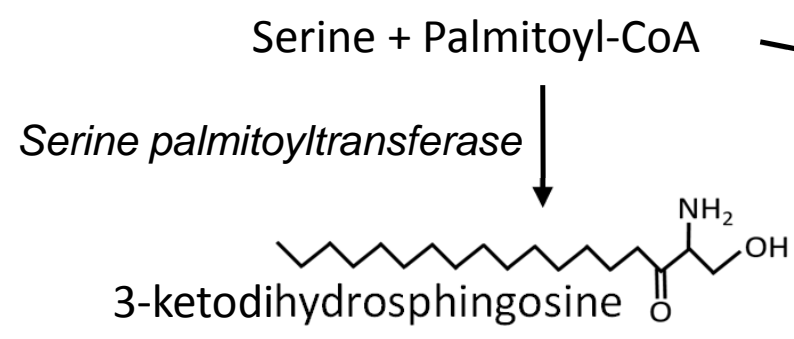

3-ketodihydrosphingosine reductase

(NADPH)

Dihydrosphingosine
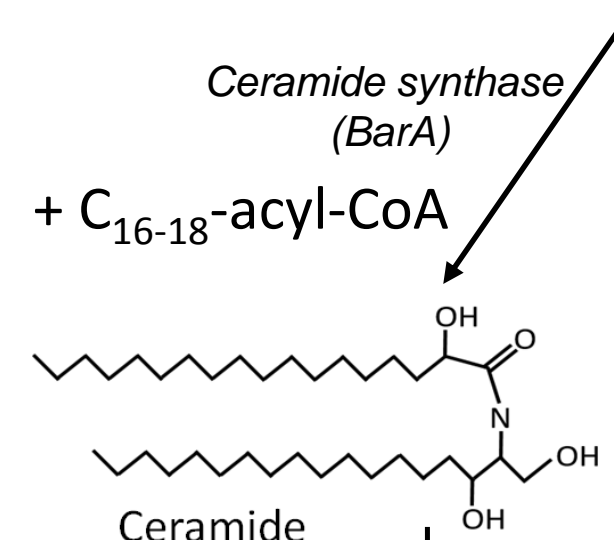

Ceramide

44-desaturase

$\Delta 8$-desaturase

C9-methyltransferase<smiles>CCCCCCCCCCCCCCCCCCC(O)C(=O)NC(CO)C(O)C=CCCC=C(C)CCCCCCCCC</smiles>

Glucosylceramide

Synthase (Gcs1)

Glucosylceramide
(DHS)

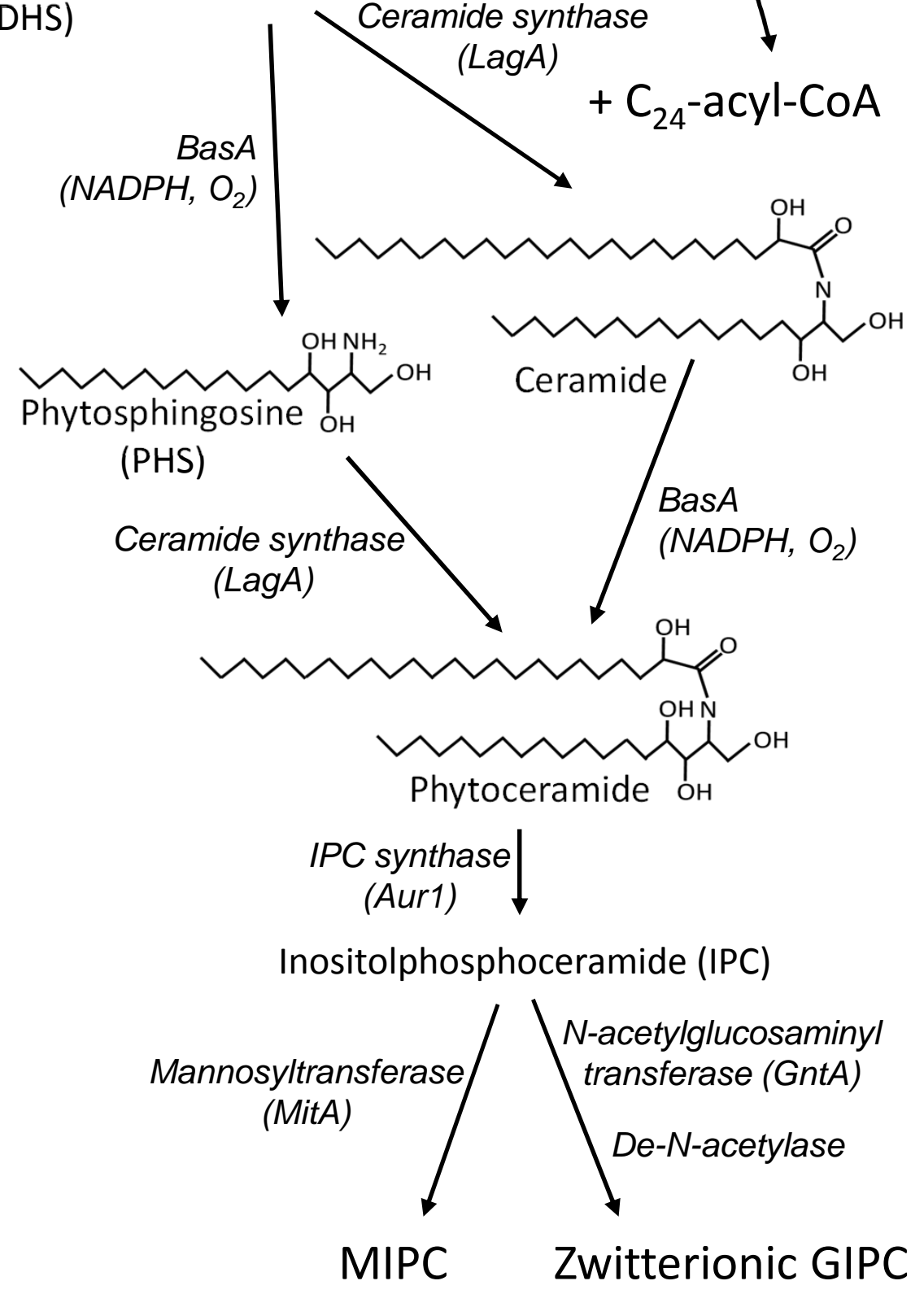

Figure 2 
Highlights

- A. fumigatus produces 3 types of sphingolipids : hexosylceramide, inositolphosphoceramide and glycosylphosphatidylinositol anchor.

- Sphingolipids from A. fumigatus follow three different biosynthetic pathways

- Fungal sphingolipids are required for virulence 